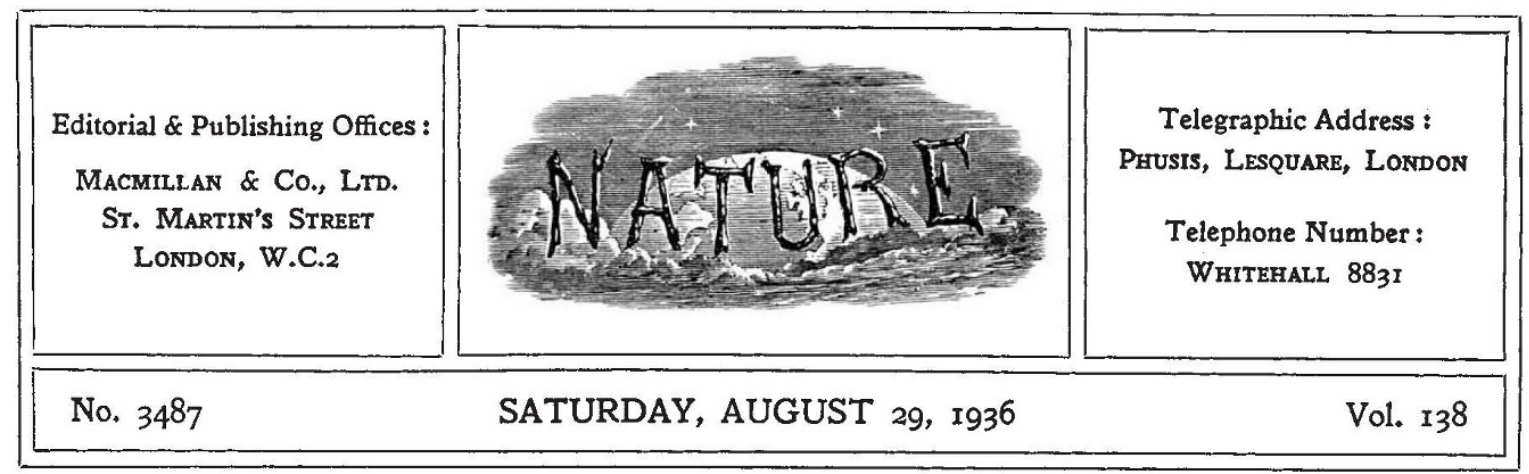

\title{
International Economics and Social Reconstruction
}

$\mathrm{T}^{\mathrm{H}}$ HE narrow outlook which continues to characterize much of the controversy regarding sanctions, the refusal to face the implications of collective security, and the disposition to blame a mere organization such as the League of Nations for failures due to lack of courage and foresight on the part of statesmen in using the machinery ready to their hand, should dispel any optimism that we are beginning to grasp the essential principles upon which the future wellbeing of mankind must be constructed. We may well doubt that there is sufficient political sense and stability in Europe or Asia to make world recovery possible at all. To those who maintain that our whole civilization is slipping into disintegration and dissolution from which all our mastery of the material universe is impotent to preserve it, a satisfactory answer is not readily found.

Reasons such as these, and the way in which the continued difficulties experienced by our own and other Governments in handling international affairs betray lack of capacity for real leadership and foresight, may well lead to misgivings as to the future in spite of the undoubted fall in unemployment and increase in industrial employment and trade. How well-founded are such misgivings is indicated. by the admirable survey of world economic and social conditions provided by Mr. Harold Butler, Director of the International Labour Office, in his Annual Report*. It is clear from this survey that no certain answer can yet be given to the question whether the past year should be regarded as marking the emergence of the world into the flowing tide of recovery or as merely an interlude of mitigated depression.

* Report of the Director, International Labour Office, Geneva, 1936
On the credit side of the economic balance sheet must be set a gradual improvement in prices and a continued decline in unemployment. In many countries, the general index of industrial production has moved steadily upwards; but in so far as this industrial prosperity is founded on the expansion of armaments, which notoriously is taking place in the principal industrial countries, it is hollow and unusual as well as sinister. The manufacture of arms adds nothing to national wealth, and the economic consequences of rearmament must be set in the scale against the apparent sign of economic revival. The universal alarm and anxiety which accompany intensive competition in armaments check the expansion of healthy trade and invest. ment, and block the path of normal recovery.

The armament situation itself is thus reason enough for some misgivings about the present situation. The slight improvement in the volume of international trade, and the extent to which economic nationalism continues to hold the field, are other reasons for anxiety. Confidence in foreign investment is still lacking, and the major obstacle to the re-birth of confidence is the fear of war, imminent or not remote ; and economic recovery is an impossible dream until this fear of another and more catastrophic collapse of the whole international political system has been dispelled.

Given a general will to seek that end in a constructive and co-operative spirit, the task is not yet impossible in spite of its increased difficulties ; but it calls for the display of statesmanship of the highest order. It must be realized that the most radical flaw in the recent peace settlement was the failure to ensure economic and social equilibrium. Territorial claims and armament programmes are the symptoms-not the causes-of our present 
condition. The roots are to be found in actual or threatened impoverishment, declining standards of life, insecurity for the future of themselves and their children which darkens the outlook of the present generation in so many countries. The question of peace can no longer be discussed apart from that of social justice.

On such grounds as these, Mr. Butler is led to a point of view which many scientific workers have reached, from their survey of the possibilities of the applications of science being utilized to raise the general standards of and amenities of human life, and to assist in the distribution of the economic resources now at our disposal. No longer can we think of life in terms of sub-divisions only. Artificial barriers which hamper our thought about men in society must be broken down and a synthesis of all the social sciences achieved which will permit a true notion of the structure and possibilities of society, just as it is only by a synthesis of all the sciences concerned with man and his environment that we can understand his nature.

Mr. Butler's brief summary of the immediate problems of social reconstruction which call for consideration has points in common, such as housing, with those which in Great Britain are already receiving the attention of such groups as P.E.P. (Political and Economic Planning), or nutrition, on which scientific workers have done much to provide a basis for action. Mr. Butler refers to the way in which these questions are linked to those of international trade and finance. The question of raw materials is similarly linked and is not even mainly a colonial problem. The countries which have real difficulties in procuring their supply of raw materials are those which have imposed restrictions in dealings in foreign exchange, due to their monetary or commercial policies. The problem cannot be divorced from the whole question of restrictions on commerce, including the question of the 'open door' in colonial territories which are large providers of certain raw materials.

These problems in themselves raise broad questions of colonial policy, not only in regard to raw materials but also in regard to labour and migration. The need for investigating such problems is now becoming generally admitted, and they can only be dealt with on practical lines if account is taken not only of general principles, such as are embodied in the Mandates Article of the Covenant of the League of Nations, but also of the conditions and requirements of each particular case. Not the least untoward consequence of Italian aggression in Abyssinia is the way in which it has enhanced the difficulties of an impartial and adequate treatment of questions which were already sufficiently thorny.

Last and most important of all in the programme of reconstruction is the problem of liberating commerce from the restrictions which have been imposed upon it by nationalist economic policies or on account of currency disorders. From whatever angle we approach the problem of reconstruction, the only path leading to its solution is that of closer international intercourse. The doctrines of nationalism and self-determination may within limits be beneficial and stimulating in the field of politics and culture, but in the field of economics they are fatal. Economic nationalism in its recently developing forms is incompatible with economic stability and therefore with the peace of the world.

The only way out of our troubles is, therefore, to restore so far as possible exchange of goods, services, money and population on which pre-War prosperity was founded, and which the rapid progress in means of communication has made all the more imperative. The new world economy to be built up, however, must take account of all the developments which have taken place since 1914 . The great internal transformation in industry and agriculture cannot be set aside without causing still further confusion and upheaval. They necessitate a complete readjustment of method, but the ultimate objective is unchanged.

Mr. Butler gives us once more a survey which commends itself to the scientific worker alike for its presentation of the facts on a broad canvas free from the distortion of material or party bias as for its insistence on the necessity of viewing life as a whole. Economics cannot be separated from ethics, social justice from material well-being, or social and ethical aspirations from political activities. Peace itself is not possible without social justice between nations and between individuals, and only through an equitable organization of the world's economic life can peace and justice and freedom be made secure.

These views to-day are in danger of becoming platitudes, though they touch the quality and direction of scientific life and thought as of every other intellectual or physical activity. It is only as creative thought is brought patiently and im. partially to bear on these questions that we can 
hope to find the lines of a solution; and the major question is whether sufficient moral and social pressure can be mobilized in support of constructive policies in which science plays its fitting part, before the reactionary forces of militarism and economic rivalry and autarchy bring the whole fabric of our civilization to collapse.

The root question behind this appeal for world co-operation is the choice between freedom and slavery of the spirit. Freedom of thought and speech, belief and investigation, subject only to the recognition of the same liberty on the part of others, is exactly what is threatened by the new tyrannies which, through their militarism and economic nationalism run mad, seek often in subtle ways to reduce the citizen to a soulless unit, to moral and intellectual servitude. The perpetuation of economic antagonism and military rivalries is as grave a danger to scientific thought and investigation, upon which so many of its material achievements are based, as it is to the continuance of our material civilization.

\section{Manifolds of Plenary Space}

\section{Intrinsic Geometry of Ideal Space}

By Dr. A. R. Forsyth. Vol. 1: pp. xxvi +553 . Vol. 2 : pp. xiv +655 . (London: Macmillan and Co., Ltd., 1935.) 2 Vols. $£ 66 s$. $0 d$. net.

$\mathrm{T}$ is desirable to give the reader immediately an idea of what is an ideal space and its intrinsic geometry. Prof. Forsyth writes: "The present work is occupied with investigations of those intrinsic properties and differential measures of geometrical amplitudes which are connected with the corporate characteristics and the organic constituents of the amplitudes". Hence we see, if we do not know what is an ideal space, we know at least that we can substitute the word "amplitude" for it ; and instead of "intrinsic" we can use "corporate" and "organic". That is all. We must seek an interpretation of these mysterious words going through the 1248 pages of this work. Before we can do that, we must become acquainted with some other words: plenary uncurved or homaloidal (Euclidean space) ; flat and block (Euclidean spaces of dimensions three and four); amplitude (manifold); regions and domains (manifolds of three and four dimensions); tilt and coil (third and fourth curvature); gremial, orbicular, and globular curvatures; and other curiously used words.

Passing over Eleusinian statements like this: "The homaloidal space is free from all native measures that can modify the geometrical character of included figures : its standardising influence is impartially neutral", we begin to examine the contents.

Section I, after an introduction where we discover the identity between homaloidal and Euclidean space (How can that be? Was it not free from any native measure?) and where we find the old Frenet equations, gives a sketch of Rieman- nian geometry (geodesics, Riemann's curvature), with a mixture of properties not belonging to this geometry but to the ordinary Euclidean geometry of the manifold (as embedded in a Euclidean space). Such are the researches on the locus of the centres of first curvatures of geodesics of a manifold $V_{n}$ concurrent at a point: the cases when the dimensions of the plenary space (Euclidean space embedding the $V_{n}$ ) are $n+2$ or $n+3$ are discussed. In this second case two subcases arise; but no hint is given of the projective ground on which this distinction stands. Neither is there any suggestion of what may happen when that space has more than $n+3$ dimensions, although the number of possibilities is finite.

With Section II begin the limitations of the field of research; the author restricts his studies to surfaces (Section II), regions (Section III) and domains (Section IV) and to their subamplitudes. Here also we find properties of Riemannian character (geodesics, Riemannian curvature, LeviCivita's parallelism, minimal surfaces and regions) scattered in different chapters, according to the dimensionality of the amplitude ; also, when they are independent of it, mixed up with properties relating the amplitude to its Euclidean space. There is a wealth of particular results (new or not, that is difficult to state from quotations in the book), but no general idea. It is a kind of empirical 'going on', step after step, with apparently no goal to be reached. The method of attack has also the same empirical character : it would certainly be inadequate for a research of broader frame.

Now some selected topics. Section I contains some theorems which can be summarized as follows: the second, third and fourth normal of a geodesic of an amplitude (at a point) lie in the tangent homaloid of the amplitude. This is a serious mistake, and no calculations are necessary 